\title{
The Study of the Heating Load Distribution of Bulk Curing Barn
}

\author{
Zhu Jian*, Chen Yingying, Yao Yao \\ School of Civil and Hydraulic Engineering, Hefei University of Technology, Hefei, China \\ Email address: \\ 244532273@qq.com (Zhu Jian), 1554161256@qq.com (Chen Yingying) \\ ${ }^{*}$ Corresponding author
}

\section{To cite this article:}

Zhu Jian, Chen Yingying, Yao Yao. The Study of the Heating Load Distribution of Bulk Curing Barn. International Journal of Industrial and Manufacturing Systems Engineering. Vol. 3, No. 5, 2018, pp. 35-41. doi: 10.11648/j.ijimse.20180305.11

Received: June 23, 2018; Accepted: July 13, 2018; Published: January 16, 2019

\begin{abstract}
This paper aims to analyze the constitution of the heating load of bulk curing barn and the heat and mass transfer process for the whole bulk curing barn and set up the energy consumption model to explore the load distribution of bulk curing barn. The hourly load is calculated in the process of tobacco curing of Yunyan 97 as an illustration. The results show that the load distribution is mainly affected by the dehydration rate of tobacco, which is similar to the distribution of humidity load; the largest heat load appears in the later period of the color fixing stage; the envelope heating load increases with the growth of time, whose amount is $15 \%$ of the amount of the heating load of bulk curing barn.
\end{abstract}

Keywords: Bulk Curing Barn, Load Calculation, Envelope Heating Load, Humidity Load, Distribution

\section{Introduction}

China is a big country of tobacco production and consumer, and the coal curing has long been a widely adopted way of tobacco flue-curing in every smoke zone of our country. The ineffective energy consumption of coal curing is too large, polluting the environment, and uneconomic. Therefore, curing tobacco with heat pump has become a new energy saving way of tobacco flue-curing. In recent years, the air source heat pump technology is widely applied in tobacco flue-curing in bulk curing barn, instead of traditional coal-fired barn. It cuts down the building area occupied by the air source heat pump and it's easy to use [1]. What's more, there is no need for pipeline systems such as cooling towers or cooling water pump. The bulk curing barn greatly improves the working efficiency and level of tobacco flue-curing in China [2]. And the calculation of the heating load of bulk curing barn is the basis of a heat pump curing equipment type selection. The prediction of the constitution of the heating load of bulk curing barn has great influences on system design, energy saving operation and the quality of tobacco curing. Therefore, there is of great necessity and practical significance to calculate and analyze the heating load of bulk curing barn.

\section{The Feature of Tobacco Curing}

People usually harvest ripe tobacco, and in the same day cure it in the curing barn, generally every year from July to September. The higher the season temperature is when curing, the shorter the curing time is. The curing takes about 6 to 8 days as a whole cycle. The entire time for tobacco curing differs from the type and the quality and the feature of tobacco.

There are strict requirement on indoor thermal environment of curing barn in each stage to ensure the color, effective component content of tobacco leaf and so on. At present, three-step curing technique is generally accepted. The entire curing process is divided into three phases: yellowing stage, fixing color stage and stem drying stage. The temperature of bulk curing barn in yellowing stage is low $\left(36 \sim 42^{\circ} \mathrm{C}\right)$, and the quantity of moisture removal is high. The temperature in fixing color stage is relatively high $\left(42 \sim 54^{\circ} \mathrm{C}\right)$, and the quantity of moisture removal is highest. The temperature in stem drying stage is highest $\left(65 \sim 68^{\circ} \mathrm{C}\right)$, and the quantity of moisture removal is extremely small $[3,4]$. According to the color of leaf and the change of moisture, the change of leaf can be judged in material, for the purpose of curing leaf until it turns brown, dry and sweet, by regulation of the curing temperature, humidity and time through the whole curing stage. 


\section{The Determination of the Heating Load of Curing Barn}

\subsection{The Establishment of the Heating Load Calculation Model of Bulk Curing Barn}

The heating load of bulk curing barn is mainly composed of thermal load caused by outer-building envelope and the load of moisture removal caused by tobacco leaf dehydration. The thermal load caused by outer-building envelope can be calculated with the conventional heat loss formula of envelope, so the key of the determination of the heating load lies in the reasonable determination of the load of moisture removal caused by tobacco leaf dehydration.

Tobacco curing is a complicated process of heat and mass transfer, accompanied by complex physical and chemical changes. Heat pump system transfers heat to the air in curing barn in the process of tobacco curing, and tobacco absorb heat from the air, making moisture evaporate into air and then the heat is taken away by hot flowed air. The key of the determination of the heating load is to establish a reasonable energy consumption model. In many of theoretical analysis of the heat pump drying system, the heat and mass exchanging process between indoor drying air and materials is generally regarded as isenthalpic hygroscopic process. The heating required to evaporate water from air is brought into air again by water vapor. The air enthalpy remains unchanged after the evaporation of water [5], the changing process of air state is shown in figure 1.

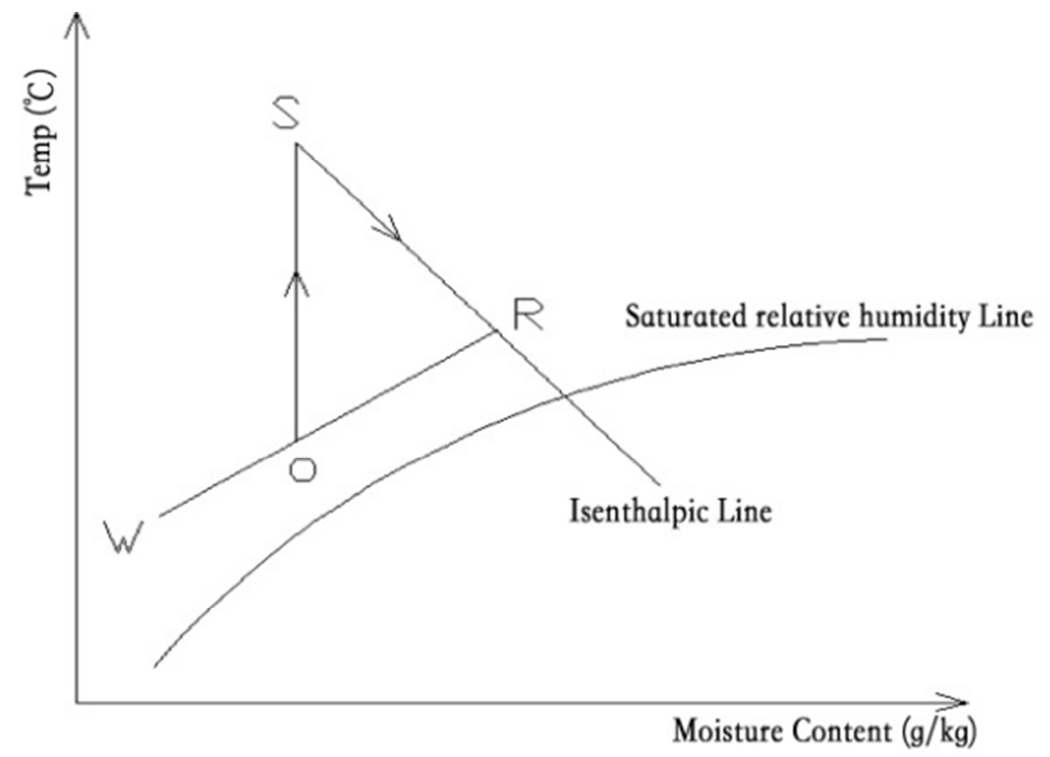

Figure 1. State change of air during the curing.

Where $\mathrm{W}$ denotes outdoor air state points, $\mathrm{R}$ denotes the air state point after its heat and mass exchanging with tobacco, $\mathrm{O}$ denotes condenser inlet air state point, $\mathrm{S}$ denotes the condenser outlet air point, namely the air supply point.

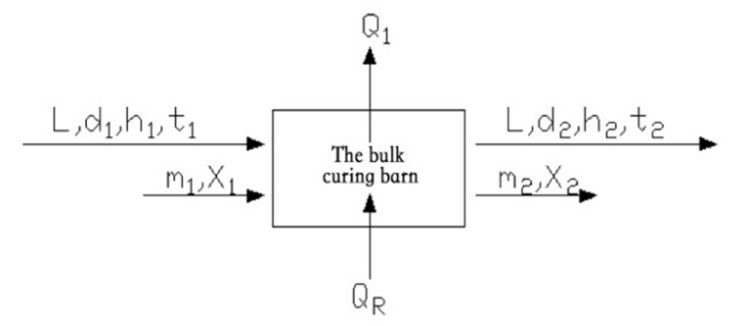

Figure 2. The heat and mass transfer model.

During curing process, a series of physiological and biochemical changes in tobacco leaves occur, producing some chemical composition good for aroma, but this part of the heat of reaction is difficult to calculate. Therefore, the tobacco and the air in curing barn can be regarded as a whole, with the boundary of the envelope of curing barn. The heat load in the process of tobacco curing can be concluded by calculating the heat and the mass between curing barn and outside conditions. The simplified heat and mass transfer process of tobacco curing is shown in figure 2 .

Where $\mathrm{L}$ denotes the mass flow rate of moist air, in and out, $\mathrm{kg} / \mathrm{h} . \mathrm{d}_{1}, \mathrm{~d}_{2}$ respectively denote the moisture content of wet air, in and out, $\mathrm{g} / \mathrm{kg} . \mathrm{h}_{1}, \mathrm{~h}_{2}$ respectively denote the wet air enthalpy, in and out, $\mathrm{kJ} / \mathrm{kg}, \mathrm{t}_{1}, \mathrm{t}_{2}$ respectively denote the temperature of air, in and out, ${ }^{\circ} \mathrm{C} . \mathrm{m}_{1}, \mathrm{~m}_{2}$ respectively denote the mass of tobacco, before curing and after curing. $\mathrm{X}_{1}, \mathrm{X}_{2}$ respectively denote the moisture content of tobacco, before curing and after curing. $\mathrm{Q}_{1}$ denotes the envelope heat loss, $\mathrm{kW} . \mathrm{Q}_{\mathrm{R}}$ denotes heating capacity of heat pump units, $\mathrm{kW}$.

\subsection{The Heating Load Calculation of Bulk Curing Barn}

\subsubsection{Curing Technology}

At present, it mainly adopts three-stage and five-step pattern in domestic bulk curing technology. There exist certain differences between different varieties of tobacco curing process curve, this article takes Yunyan97 as an example, and its three-stage and five-step pattern of bulk curing technology curve is shown in figure 3 [6], given the condition where the 
temperature and the humidity of air inside barn change over time. The speed of Yunyan97 turning yellow is slightly rapid, and it's easy to be cured. If mature tobacco is fully harvested, the temperature in yellowing stage is from 38 to $42^{\circ} \mathrm{C}$, and almost all the tobacco leaves turn yellow. The temperature in color fixing stage is from 52 to $54^{\circ} \mathrm{C}$, the tobacco leaves become dry. And the temperature in stem drying stage is no more than $68^{\circ} \mathrm{C}$, all the tobacco leaves turn dry. The envelope heating load calculation takes the temperature and the humidity given by the technology curve as the design parameters in curing barn.

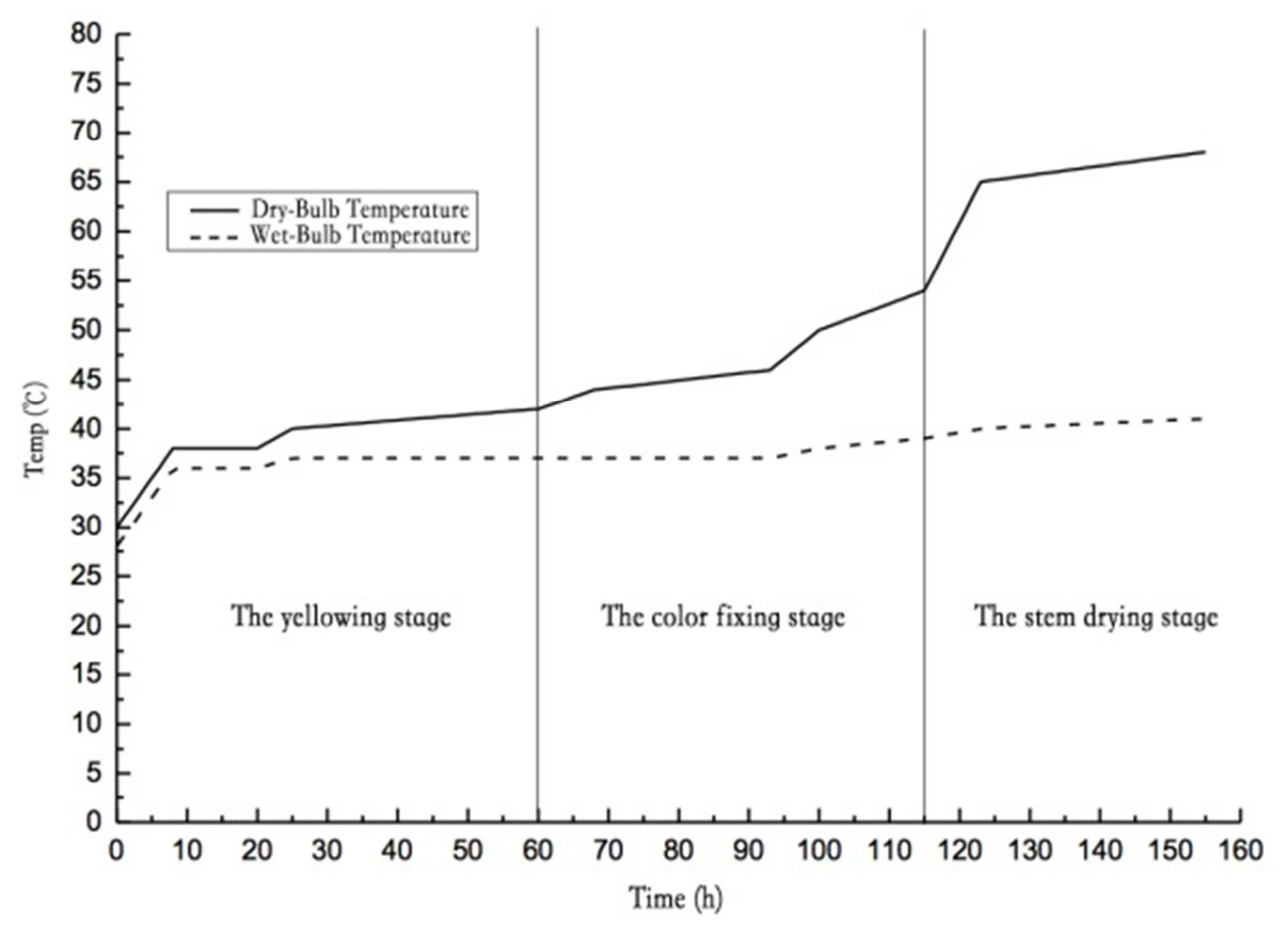

Figure 3. The curing process curves of Yunyan 97.

\subsubsection{The Calculation of the Heating Load of Envelope}

$$
\mathrm{Q}_{1}=\mathrm{AK}\left(\mathrm{t}_{\mathrm{n}}-\mathrm{t}_{\mathrm{wn}}\right)
$$

Where $\mathrm{Q}_{1}$ denotes the envelope heating load, W. A denotes calculating heating transfer area, $\mathrm{m}^{2} . \mathrm{K}$ denotes the heating transfer coefficient, $\mathrm{W} /\left(\mathrm{m}^{2} \cdot{ }^{\circ} \mathrm{C}\right) \cdot \mathrm{t}_{\mathrm{n}}$ denotes design temperature inside curing barn, ${ }^{\circ} \mathrm{C} . \mathrm{t}_{\mathrm{wn}}$ denotes calculating temperature of external environment, ${ }^{\circ} \mathrm{C}$.

Tobacco curing is a process of big heating consumption, one of the reasons of the excessive invalid energy consumption in our country is that the heating preservation of envelope is not strong enough. It can improve the thermal utilization rate to renovate the heat preservation of standard curing barn.

\subsubsection{The Calculation of the Load of Moisture Removal Caused by Tobacco Leaf Dehydration}

According to the conservation of mass, the dehydration rate calculation formula in tobacco curing process is as follows:

$$
\mathrm{G}_{\mathrm{w}}=\mathrm{L}\left(\mathrm{d}_{2}-\mathrm{d}_{1}\right)
$$

Where $G_{w}$ denotes the dehydration of tobacco leaf, $\mathrm{kg} / \mathrm{h}$. L denotes the air mass flow, flowing in and discharge the curing barn, can be calculated according to this formula.

The situation of tobacco dehydration in the curing process is roughly as follows: the dehydration rate in yellowing state, is from $27 \%$ to $35 \%$, the fixing color stage is from $50 \% \sim 55 \%$, and the stem drying stage is from $10 \%$ to $23 \%$ [6-8]. The detailed dehydration rates [9] in the process of tobacco curing are shown in table 1 .

\begin{tabular}{|c|c|c|c|c|c|c|c|}
\hline \multirow{2}{*}{$\begin{array}{l}\text { Curing process } \\
\mathrm{T}\left({ }^{\circ} \mathrm{C}\right)\end{array}$} & \multicolumn{3}{|c|}{ Yellowing stage } & \multicolumn{2}{|c|}{ Color fixing stage } & \multicolumn{2}{|c|}{ Stem drying stage } \\
\hline & $30 \sim 36$ & $36 \sim 38$ & $38 \sim 42$ & $42 \sim 48$ & $48 \sim 54$ & $54 \sim 60$ & $60 \sim 68$ \\
\hline Dehydration rate $\left(\% /{ }^{\circ} \mathrm{C}\right)$ & 0.8 & 5.11 & 3.64 & 3.61 & 3.28 & 0.11 & 0.23 \\
\hline
\end{tabular}

Table 1. Dehydration rate during the curing [9].

Through summing up the above rules, the dehydration rate can be simply calculated combining with the technology curve.

The dehydration rate of yellowing stage, fixing color stage and stem drying stage are $31 \%, 52.5 \%$ and $16.5 \%$ respectively, and then it is combined with every stage of the table 1 to allocate dehydration rate, and finally to determine the dehydration rate of each stage, as is shown in table 2 (the value in the table is the proportion of total water loss). 
Table 2. Dehydration rate of each stage.

\begin{tabular}{|c|c|c|c|c|c|c|c|}
\hline \multirow{2}{*}{$\begin{array}{l}\text { Curing process } \\
\mathrm{T}\left({ }^{\circ} \mathrm{C}\right)\end{array}$} & \multicolumn{3}{|c|}{ Yellowing stage } & \multicolumn{2}{|c|}{ Color fixing stage } & \multicolumn{2}{|c|}{ Stem drying stage } \\
\hline & $30 \sim 36$ & $36 \sim 38$ & $38 \sim 42$ & $42 \sim 48$ & $48 \sim 54$ & $54 \sim 60$ & $60 \sim 68$ \\
\hline Dehydration rate $\left(\% /{ }^{\circ} \mathrm{C}\right)$ & 0.826 & $5 . .347$ & 3.837 & 4.585 & 4.165 & 0.726 & 1.518 \\
\hline
\end{tabular}

The load of moisture removal caused by tobacco leaf dehydration, $\mathrm{Q}_{\mathrm{p}}$ can be calculated by follow formula:

$$
\mathrm{Q}_{\mathrm{p}}=\mathrm{L}\left(\mathrm{h}_{2}-\mathrm{h}_{1}\right)
$$

The heating load of bulk curing barn is the sum of the thermal load caused by outer-building envelope and the load of moisture removal caused by tobacco leaf dehydration:

$$
\mathrm{Q}_{0}=\mathrm{Q}_{1}+\mathrm{Q}_{\mathrm{p}}
$$

\section{A Calculation Example}

This calculation model, put forward in this paper, calculates the curing heating load, taking Yunyan97 in the south Anhui province as an example. Its three-stage and five-step type of bulk curing technology curve is shown in figure 3 , located at
Xuancheng city, and it adopts DeST simulation to calculate the envelope heating load.

Calculation conditions illustration:

Yunyan97, has its mass $4000 \mathrm{~kg}$ before curing, has curing time $155 \mathrm{~h}$, actually in the production process of tobacco, people usually harvest ripe tobacco, and in the same day cure it in the curing barn (people harvest ripe fresh tobacco in the morning, weave in the afternoon and start to cure in the evening [8]). Therefore, a cycle from 18:00 on July 3 to 5:00 July 10 is chosen to estimate the heating load of curing barn.

\subsection{The Heating Load Calculation of Bulk Curing Barn}

The basic structure and parameters [10] of the curing barn is as follows:

Table 3. The structure and parameters of curing barn.

\begin{tabular}{ll}
\hline Name & Structural and parameters \\
\hline Leaf loading room & Length 8000 , width 2700 , height 3540 \\
Machine room & Length 4000 , width 2700 , height 3540 composed of support pillar and roofing, united with leaf loading room \\
Wall & $240 \sim 400 \mathrm{~mm}$ unburned solid brick \\
Roofing & $100 \sim 120 \mathrm{~mm}$ reinforced concrete with thermal barrier \\
Door & Double-open door, height 3000, width 2700 , color plate insulation board \\
Window & $1600 \times 300 \mathrm{~mm}$, double glazing unit, on the left of leaf loading room's rear wall \\
\hline
\end{tabular}

The curing barn model is set up in DeST, the envelope load from July 3 to July 10 was hourly simulated, and simulation results are shown in figure 4.

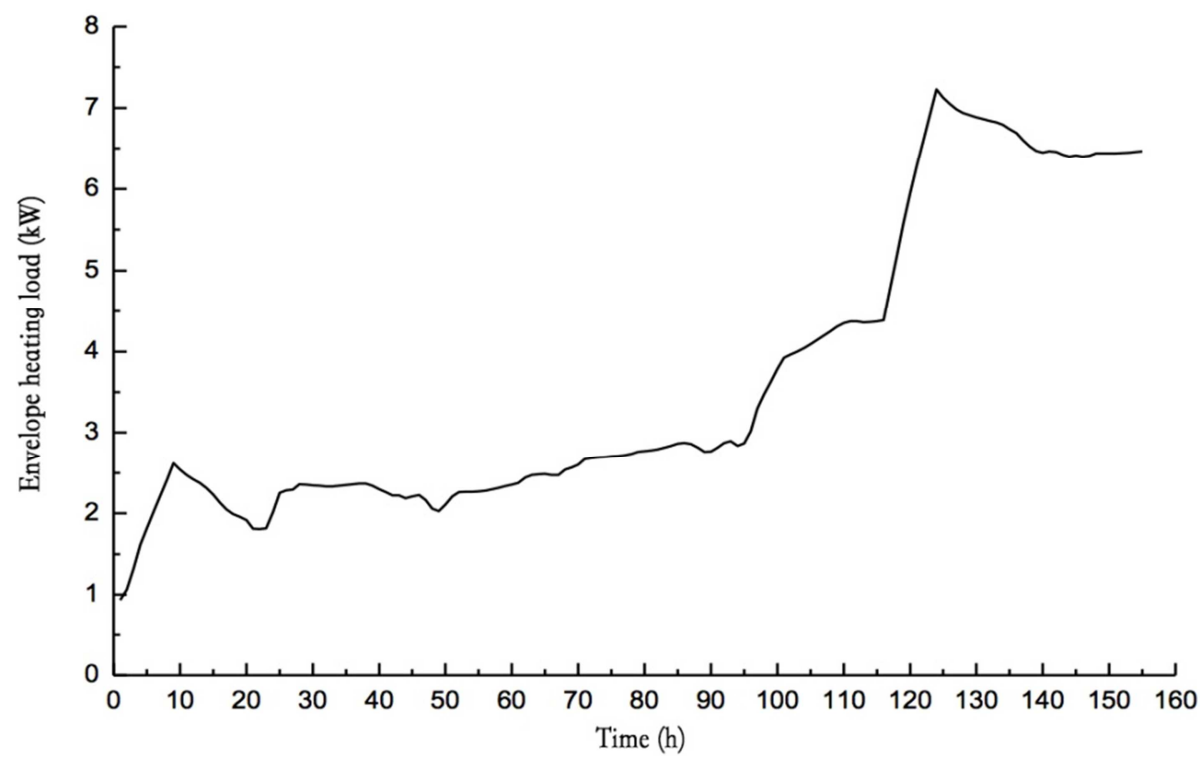

Figure 4. The envelope heating load of curing barn.

As in shown in the simulation results, the heating load value of the curing barn envelope overall increases with the rising of temperature in curing barn, the peak value is $7.23 \mathrm{~kW}$, it appeared on July 8 at 21:00, the main reason is that it is affected by the hourly simulation meteorological parameter values. In the curing process, the accumulative envelope heating load total $562.63 \mathrm{~kW} \cdot \mathrm{h}$. 


\subsection{The Calculation of the Heat Loss of Moisture Removal Caused by Tobacco Leaf Dehydration}

Yunyan97 is originated in central China, and the moisture content of fresh tobacco leaf is commonly in $85 \% \sim 90 \%(88 \%$ is used), and the moisture content at the end of curing is about $6.5 \%$, according to the dehydration rate as is shown in the table 2, the corresponding dehydration trend is calculated, as shown in figure 5 . As is shown in the figure, the dehydration rate reaches its maximum in color fixing stage, next maximum in yellowing stage and minimum in the stem drying stage.

The air mass flow, flowing in the curing barn, $\mathrm{L}$ and the load of moisture removal caused by tobacco leaf dehydration, $Q_{p}$ are calculated, according to formula (2), (3). How L and $Q_{p}$ change over time is shown in figure 6 and figure 7.

In initial time of curing, the relative humidity inside curing barn is lower than the technical requirements, so no fresh air come in, until the air of closed curing barn is heated and the relative humidity meets the technological requirements. So that the temperature and humidity of barn can meet the technological requirements. The duration of airtight heating stage is less than 5 minutes as calculation, compared with the whole curing process $155 \mathrm{~h}$, its effect is so small that it can be overlooked for discussion purposes.

It shows that the change trend of fresh air curve in the curing process is the same as that of the dehydration rate. In the early period of yellowing stage, the temperature rises rapidly (it reaches $36^{\circ} \mathrm{C}$, as is shown in figure 3) and the tobacco also lose a large amount of water. At the same stage, the difference of moisture contents between indoor and outdoor air is small, so that large air volume is required. In the middle of yellowing stage $\left(38 \sim 42^{\circ} \mathrm{C}\right)$, the mass flux of air remains at around $600 \mathrm{~kg} / \mathrm{h}$. In the early period of color fixing stage $\left(42 \sim 48^{\circ} \mathrm{C}\right)$, the mass flux of air is around $1300 \mathrm{~kg} / \mathrm{h}$, and in the later period $\left(48\right.$ to $\left.54^{\circ} \mathrm{C}\right), 1800 \mathrm{~kg} / \mathrm{h}$. The maximum, $2120 \mathrm{~kg} / \mathrm{h}$, also appears in this stage. The mass flux of air in stem drying stage remains at 400 to $500 \mathrm{~kg} / \mathrm{h}$.

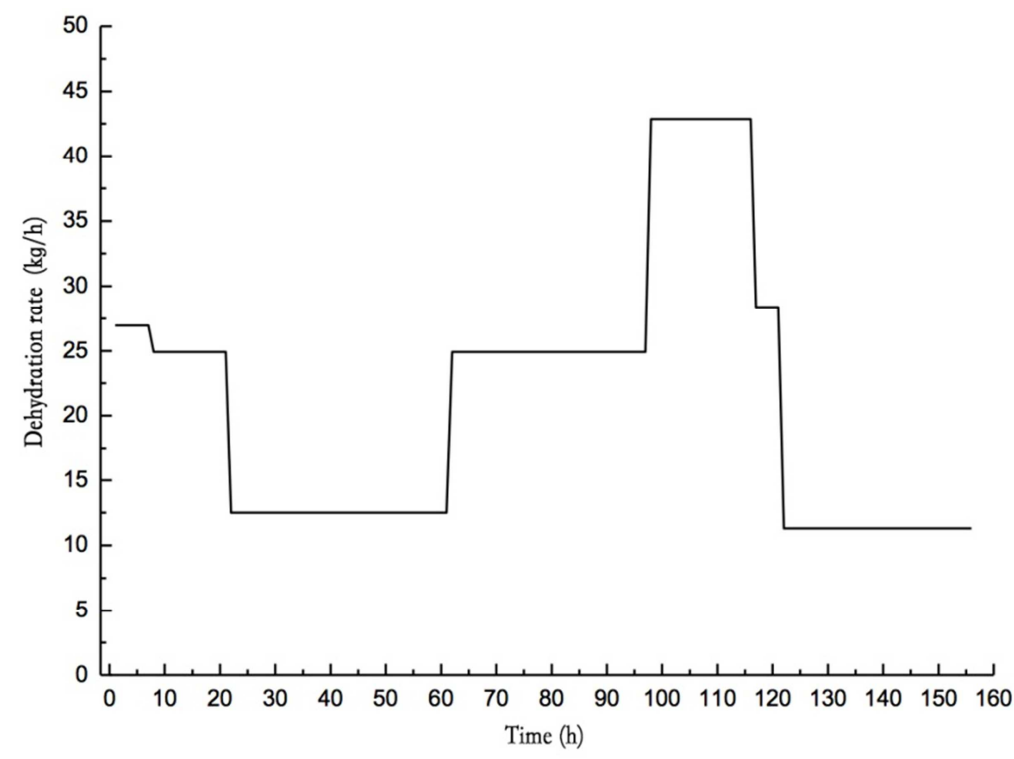

Figure 5. Dehydration rate in tobacco.

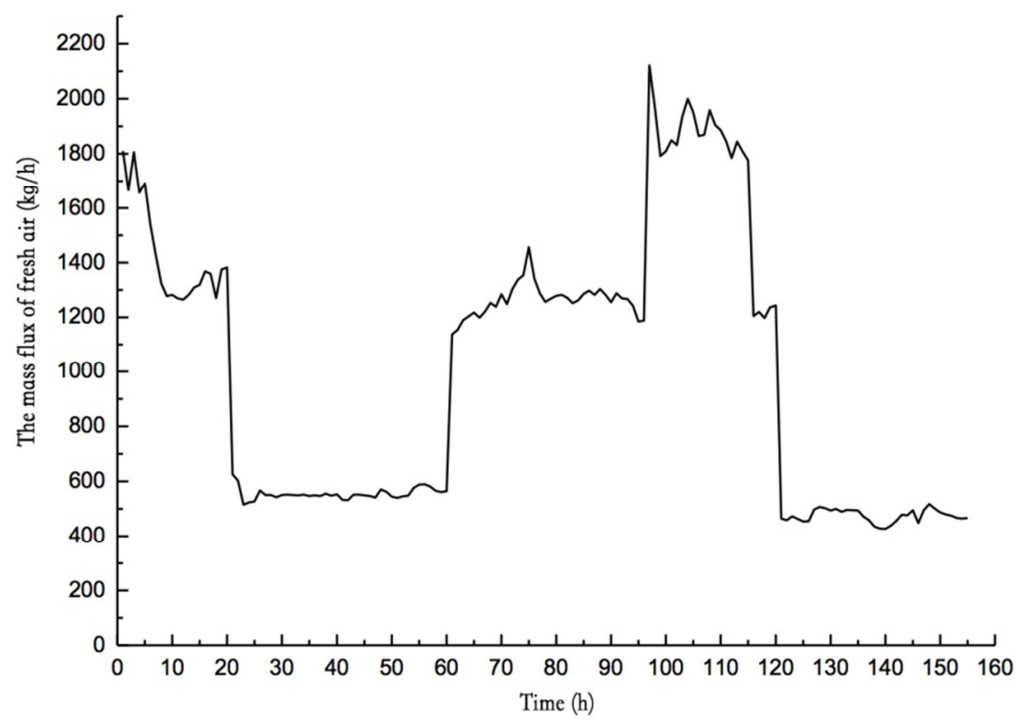

Figure 6. The mass flux of fresh air entering to the curing barn. 


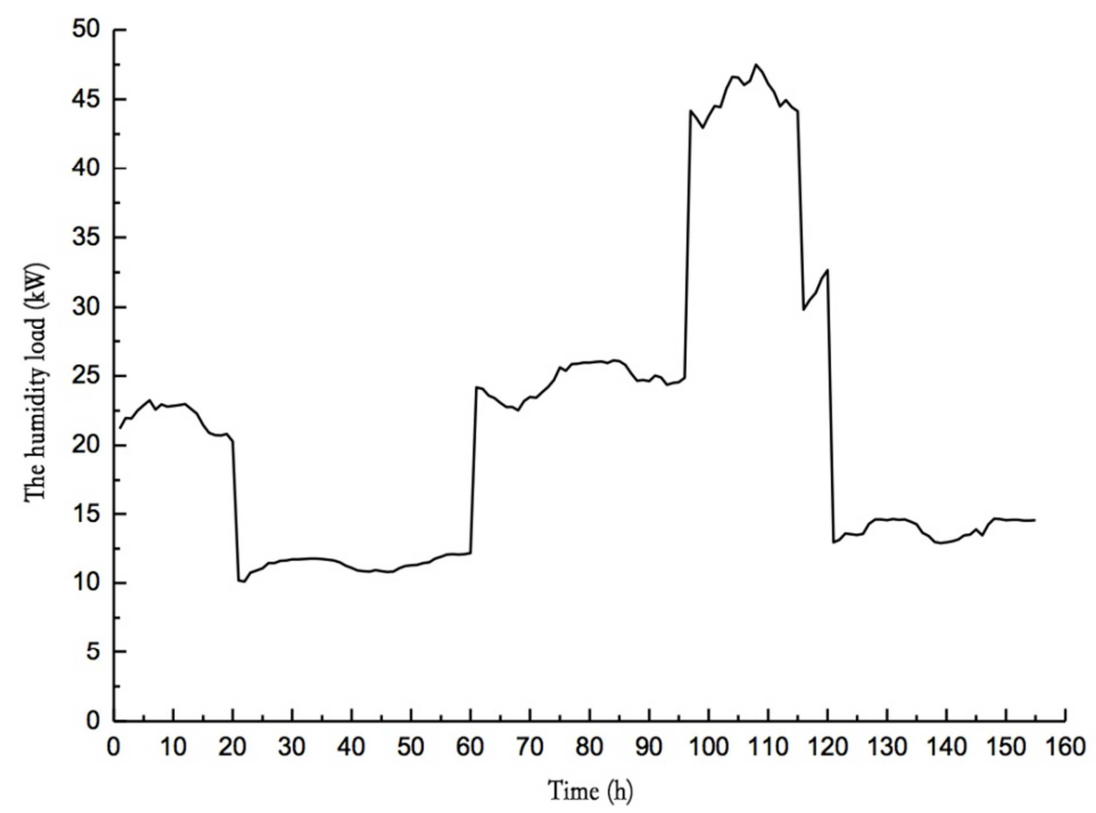

Figure 7. The humidity load.

The heat loss of moisture removal caused by tobacco leaf dehydration and the mass flux of fresh air entering to the curing barn are both proportional to the air enthalpy difference between inside and outside curing barn. In situations where the curing technology curve has been determined, outdoor air state parameters are the main influences. As shown in figure 7, the largest heat loss of moisture removal reaches $47.49 \mathrm{~kW}$, it appears in the later period of color fixing stage.

\subsection{The Heating Load of Bulk Curing Barn}

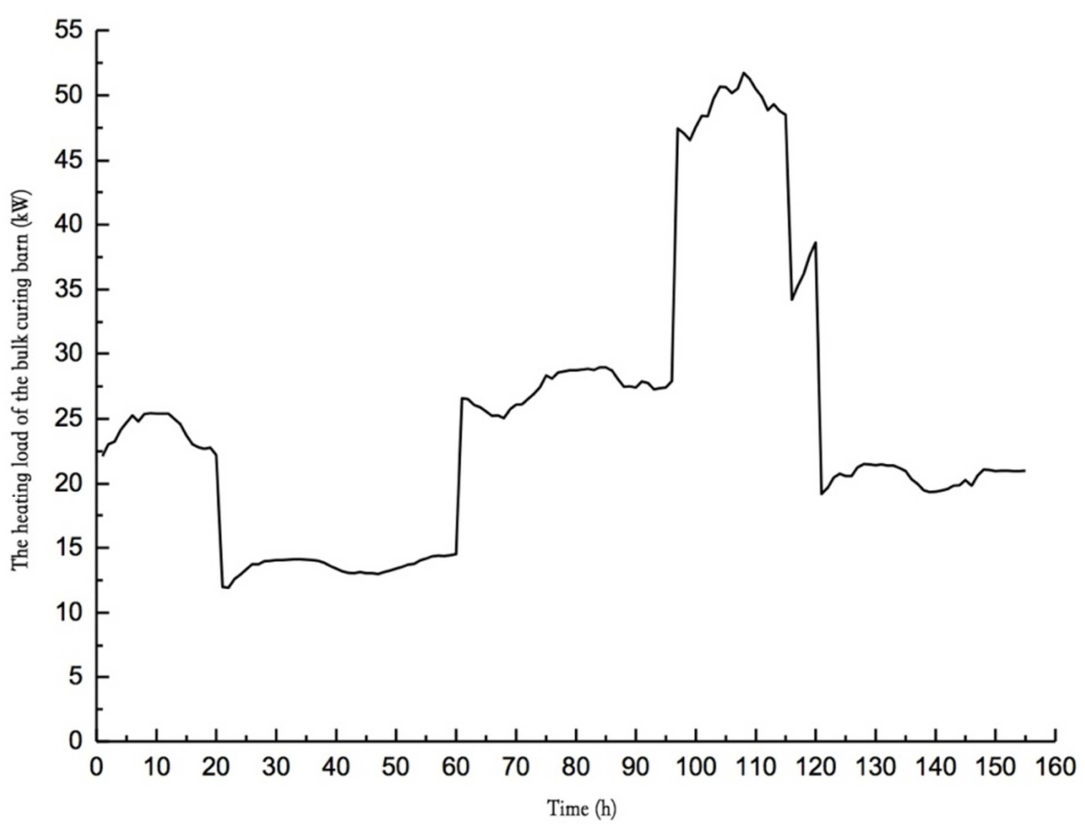

Figure 8. The heating load of bulk curing barn.

In conclusion, according to the formula (4), the heat load of curing barn changes with time is as shown in figure 8 .

The changing law of the heating load of curing barn is similar to that of the heat loss of moisture removal, namely, the heating load of curing barn is mainly depends on dehydration rate. The largest heat load reaches $51.74 \mathrm{~kW}$, it appears in the later period of color fixing stage, and in the same stage, the heat loss of moisture removal is $47.49 \mathrm{~kW}$, accounting for $91.8 \%$ of all the heating load, the average load reaches $24.83 \mathrm{~kW}$. The humidity load reaches $3285.32 \mathrm{~kW} \cdot \mathrm{h}$, accounting for $85.4 \%$ of all, the envelope heating load reaches $562.63 \% \mathrm{~kW} \cdot \mathrm{h}$, accounting for $14.6 \%$ of the total load. 


\section{Conclusion}

In this paper, the heating load calculation of bulk curing barn is briefly analyzed. The heat and mass transfer process for the whole bulk curing barn is simply analyzed, and the energy consumption model is set up. The load is hourly calculated in the process of tobacco curing, taking Yunyan97 as an illustration.

The results show that the law of curing barn's load distribution is similar to the law of humidity load distribution. The largest heat load appears in the later period of color fixing stage. The envelope heating load amount accounts for $14.6 \%$ of the entire heating load amount of bulk curing barn, which must not be overlooked. It is not advisable for some literature say that the envelope load has a small and negligible percentage than humidity load which can be overlooked.

The difficulty of determining curing barn heating load lies in determining dehydration rate of tobacco leaf in curing process. Different kinds of tobacco and different technology curves both have an influence on dehydration rate. Detail dehydration rates of each kind of tobacco are required to gain a more precise calculation.

\section{References}

[1] Tang Juan, Li Kuining. Heat pump air conditioning technology based on renewable energy [J]. Refrigeration and air conditioning (sichuan), 2007, 21 (4): 62-65.

[2] Yangyan. Study on application advantages and economic benefits of bulk curing barn[J]. South China Agriculture, 2016:248-250.
[3] Yan Ming, Yu Junqiang, Zhang Lizhi. Research progress on heat and humidity recovery and utilization of flue-cured tobacco houses [J]. Agricultural mechanization research, 2010 (5): $247-252$.

[4] Ma Cuiling, Li Fulin, Cui Guomin. Dynamic change rule of leaf moisture in different types of roasts [J]. China agricultural science bulletin, 2007, 23 (6): 630-633.

[5] Lu Jun, Wei Juan, Zhang Zhentao. Theoretical analysis and comparison of the performance of the heat pump flue-cured tobacco system based on the process of constant enthalpy and isothermal process [J]. Journal of agricultural engineering, 2012, 28 (20): 265-271.

[6] Xu Feng. Key points of the three-stage baking technology (figure) [J/OL]. [2011-07-13]. http://www.tobaccochina.com/tobaccoleaf/curing/curing/2011 7/20117814271_472710.shtml.

[7] Zhao Mingqin, Gong Changrong, Wang Yaofu. Study on the water loss rule of tobacco leaves under different baking conditions [J]. Journal of henan agricultural university, 1995, 29 (4): $382-387$.

[8] Gong Changrong, Wang Xiaojian, Ma Jingmin. Study on the relationship between water dynamics and physiological changes in leaf tobacco during roasting [J]. Journal of henan agricultural university, 2000, 34 (3): 29-231.

[9] Zhao Huawu. Study on moisture, electrical properties and wind speed changes of flue-cured tobacco leaves during intensive roasting [D]. Zhengzhou, henan agricultural university, 2012.

[10] Q/GDYY 019-2011, technical specifications for the construction of intensive bake houses [S]. Guangdong province company, China tobacco corporation, Beijing, China standards press, 2011:5. 